\section{scientists are cracking the glass ceiling}

$\mathrm{N}$ orway, a nation already known for its progressive strides in gender equality, in 2006 enacted a law designed to help women crack one of the most doggedly male-dominated arenas of all: the corporate boards of companies listed on the Oslo Stock Exchange were told to include at least $40 \%$ women, or risk being dissolved. Today, eight years on, what has this controversial quota achieved? And how have materials scientists, and the firms they work for, benefited?

Mari Teigen, research director at the Centre for Research on Gender Equality in Oslo, is completing a study on the effects of the quota. "There has been a slight positive effect, but there are still very few women in top positions," she says. The law affected around 500 publicly listed companies, with most complying by 2008. Many of these are oil and gas companies, while a few are mining and renewable energy firms, tingent of materials scientists and engineers among their workforce.

Ingrid Elisabeth di Valerio, on the board of directors of the Norwegian oil and gas company Statoil, says, "I firmly believe that without the quota law in corporate boards, we would not reach near $40 \%$ before another 15 years at least. In 1993 the percentage of women in corporate boards was $3 \%$, and [it was] $7 \%$ in 2003 when the quota law was introduced." Di Valerio-a materials engineer in the firm's technology, projects, and drilling division-is one of three people on the board who were elected by the employees of Statoil. Notably, two of these three elected members are women.

Among the justifications for introducing the law, which was seen by some which means that there is a strong con-

as too heavy-handed a form of positive discrimination, was not only the need for greater female representation, but also the belief that having gender-equal boards would make firms more profitable. Even so, a handful of companies are believed to have delisted themselves from the Oslo Stock Exchange because of the quota.

Mimi Berdal, on the board of directors of the solar energy company REC, says that although she opposed the law in principle, she believes it has worked insofar as improving corporate governance and the competence of boards. Her career was certainly impacted by the quota. "I received many enquiries for board positions when the quota law was enacted,' she says. So many, in fact, that she had to decline some of the invitations.

Berdal's experience reflects that of a small number of highly qualified women who were flooded with offers of directorships when the quota began, and have since taken up multiple board positionsa group often referred to, somewhat condescendingly, as the "golden skirts."

The lack of women in top management in Norway is sometimes described as a paradox, says Teigen, because generous childcare policies, lengthy paternity leave, and flexible working conditions (as there

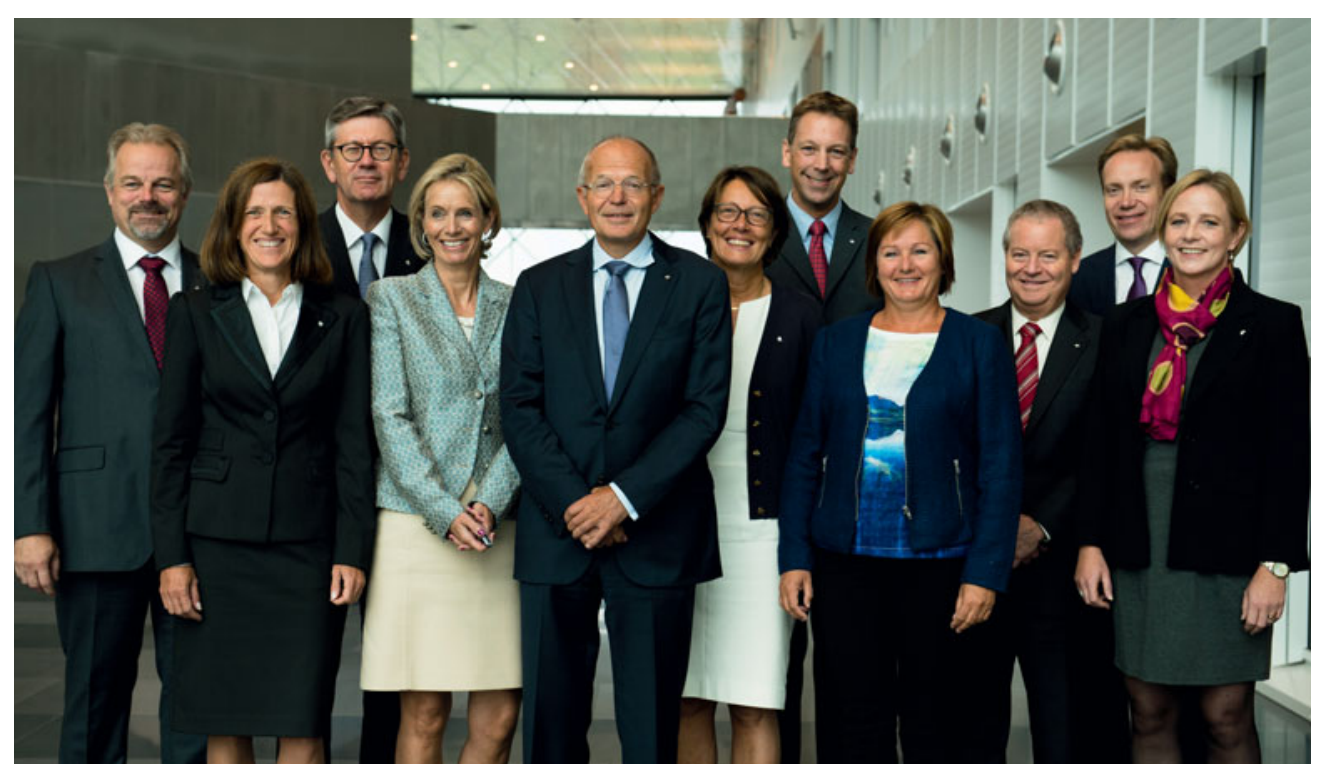

The board of directors of the oil and gas firm Statoil, in 2013, after Norway's quota law had been enacted. Ingrid Elisabeth di Valerio, a materials engineer, is on the far right. Credit: Ole Jørgen Bratland/Statoil. are in all Nordic countries) ensure that women are highly employed. Women should thus be moving upwards, but they seem to hit a thick glass ceiling at the top, particularly in the corporate sector. One benefit of the quota, explains Teigen, is that the change in gender composition in boardrooms has been accompanied by a change in mentality regarding women in senior jobs, particularly among men who may have doubted their ability. 


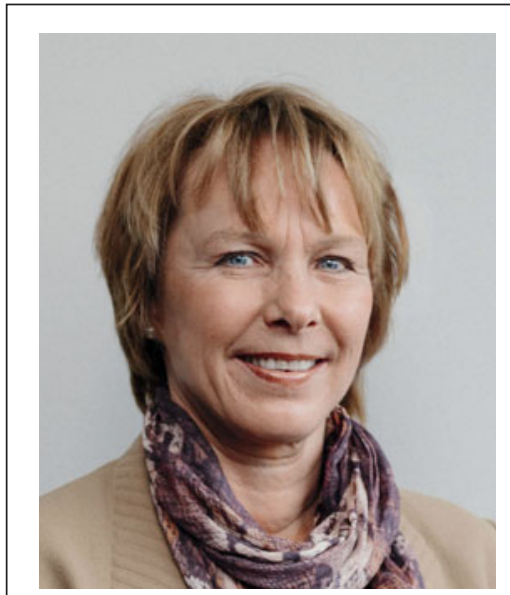

Mimi Berdal, member of the board of the Norwegian Solar Energy Firm REC. Picture courtesy of REC.

Materials science and engineering firms, however, continue to face the struggle of encouraging women through their doors in the first place, Teigen says, because it is a "male-dominated part of the labor market." Berdal disagrees.
"Due to the large impact of the oil and gas industry in the Norwegian economy, there are many highly qualified female engineering and science [candidates] available for board positions," she says.

Indeed, across science and engineering, women are better represented in Norway than in many other Western hemisphere countries. "The European Engineering Report shows that 19.7\% of engineers in Norway are women. This is about double the level in the USA, UK, and Australia," says Kathleen Buse, faculty director for the Leadership Lab for Women in STEM [Science, Technology, Engineering and Math] in the United States. Buse believes that women corporate board members can serve as positive role models and forces for cultural change, particularly in materials organizations.

"It's important to have female role models on all levels in engineering companies: female colleagues, managers, executives, and board members," adds Ingrid Elisabeth di Valerio. She herself was discouraged from entering engineering when she was younger, but persevered nonetheless.

The radical step taken by Norway has been closely followed by other European countries, starting with Spain in 2007. Iceland and France introduced similar quotas in 2010, with Belgium and Italy following in 2011, and The Netherlands in 2013. Partly as a result of these moves, the percentage of women on corporate boards in the European Union rose to a record $18.6 \%$ in 2014 , according to the European Commission. Malaysia and Brazil have meanwhile also enacted their own quotas.

"It has become evident that women actually exist who have the knowledge, competence, and capacity that are required for boardroom duty!" observes Professor Agnes Bolso, a sociologist at the Norwegian University of Science and Technology. "To question that has become illegitimate."

Angela Saini
NIST releases tool for evaluating building performance http://birdscom.nist.gov

$\mathrm{D}$ esigning a building that simply meets local code requirements is not necessarily the optimal way to do it when you consider all the long-term costs. Now, building professionals in more than 200 US cities can use a new database developed by the National Institute of Standards and Technology (NIST) to evaluate whether it pays to exceed code requirements for energy efficiency by tallying expected costs, kilowatts expended, carbon emissions, and other impacts over a planned commercial building's lifetime.

Called BIRDS (Building Industry Reporting and Design for Sustainability), NIST's new database and software tools are designed to assess three major determinants of building sustainability: energy, environmental, and cost performance.

Focusing initially on 11 building prototypes that account for about half of
US new commercial construction annually, the online data package features a "whole building measurement system." An integrated set of metrics gauges sustainability of materials and energy usage, assesses carbon footprints and 11 other indicators of environmental performance, and tabulates economic costs over nine different investment horizons.

BIRDS complements NIST's popular tool known as BEES (Building for Environmental and Economic Sustainability) that allows a user to measure economic and environmental impacts of building products, ranging from concrete to roof coverings to floor coverings.

Due to the complexity of a building and the hundreds or thousands of products that are required to construct and operate the structure, it is not feasible to use typical life-cycle assessment approaches to estimate its environmental performance.
Instead, BIRDS implements a novel hybrid life-cycle assessment (LCA) approach to evaluate the environmental performance of a building. The new tool combines two separate LCA approaches - “top-down" environmental input-output data and "bottom-up" process-based data - to calculate a more accurate environmental impact.

NIST's aim is to make LCA and life-cycle costing - analytical methods now mostly plied by specialists - more accessible with hands-on tools anyone can use to answer "what if" questions when planning or designing a new office building, retail store, or any of nine other types of commercial structures.

"Buildings are complex systems, and how they perform is not simply the sum of their many parts," says Joshua Kneifel, who led the development of the database and its measurement tools. "With BIRDS, anyone can measure and compare operating energy use through detailed simulations, materials use through innovative life-cycle inventories, and building costs over time." 